Editor's Note: These short reviews of a recent paper in the Journal, written exclusively by graduate students or postdoctoral fellows, are intended to mimic the journal clubs that exist in your own departments or institutions. For more information on the format and purpose of the Journal Club, please see http://www.jneurosci.org/misc/ifa_features.shtml.

\title{
Morphine-Induced $\mu$-Opioid Receptor Internalization: A Paradox Solved in Neurons
}

\author{
Jean Martin Beaulieu \\ Department of Cell Biology, Duke University Medical Center, Durham, North Carolina 27710 \\ Review of Haberstock-Debic et al. (http://www.jneurosci.org/cgi/content/full/25/34/7847)
}

The G-protein-coupled receptor (GPCR) superfamily of seven transmembrane domain proteins modulates a broad array of vital physiological responses ranging from sensory perception to immunity, chemotaxis, and neurotransmission. After stimulation, these receptors activate their respective heterotrimeric G-proteins, initiating cascades of intracellular signaling events. Subsequently, stimulation results in the phosphorylation of receptors by GPCR kinases (GRKs), leading to the recruitment of members of a family of scaffolding proteins termed arrestins. Two members of the arrestin family are specifically expressed in photoreceptors, whereas two others, $\beta$-arrestin- 1 and $\beta$-arrestin-2, are expressed in all other cell types. Interaction of arrestins with GPCRs (Fig. 1A) results in an uncoupling of G-protein signaling from receptors (receptor desensitization), a recruitment of the endocytic machinery leading to receptor internalization, and, in some cases, the formation of arrestin-dependent signaling complexes by which GPCRs can mediate signaling without an active participation of G-proteins (Gainetdinov et al., 2004; Beaulieu et al., 2005).

GPCR regulation by arrestins and GRKs has been studied extensively in het-

Received Sept. 15, 2005; revised Sept. 19, 2005; accepted Sept. 20, 2005. Correspondence should be addressed to Jean Martin Beaulieu, 487 CARL Building, Box 3287, Duke University Medical Center, Durham, NC 27710. E-mail:m.beaulieu@cellbio.duke.edu.

DOI:10.1523/JNEUROSCI.3914-05.2005

Copyright $\odot 2005$ Society for Neuroscience $\quad$ 0270-6474/05/2510061-03\$15.00/0 erologous cellular systems, mostly using human embryonic kidney 293 (HEK293) cells. Although this approach has allowed functional characterization of arrestins, GRKs, and other associated proteins, direct extrapolation of results obtained in these model systems to physiological GPCR responses in the CNS has remained problematic. For instance, stimulation of $\mu$-opioid receptors (MORs) by morphine in HEK293 cells does not trigger rapid receptor phosphorylation and internalization (Whistler et al., 1999). In contrast, nonrewarding opiates such as $\mathrm{D}-\mathrm{Ala}^{2}-\mathrm{N}$ Me-Phe ${ }^{4}$-Glycol ${ }^{5}$-enkephalin (DAMGO) and methadone provoke rapid internalization of MORs, suggesting that the abuse potential of morphine and development of drug tolerance may come in part from a lack of receptor internalization (Whistler et al., 1999). These in vitro observations suggest that GRKs and arrestins should play a small role in regulating the effects of morphine in the CNS. Paradoxically, mice lacking the arrestin family protein $\beta$-arrestin-2 ( $\beta$ Arr2 knock-out) display enhanced behavioral responses and G-protein-mediated signaling in response to morphine (Bohn et al., 1999). Moreover, these mice fail to develop tolerance to this drug (Bohn et al., $2000)$, indicating that $\beta$-arrestin- 2 does indeed regulate morphine responsiveness in vivo.

An article in The Journal of Neuroscience (Haberstock-Debic et al., 2005) provides a set of interesting observations that could help to solve this imbroglio. In a previous article, these authors showed that systemic morphine administration triggers a redistribution of MORs reminiscent of receptor internalization in the nucleus accumbens of rats (HaberstockDebic et al., 2003). However, it was not clearly demonstrated at the time that MOR redistribution resulted from internalization, and the possible contribution of endogenous opiates to this phenomenon was also impossible to rule out. Haberstock-Debic et al. now substantiate these findings using cultured rat striatal neurons.

The authors showed that both DAMGO and morphine cause a redistribution of endogenous MORs in cultured striatal neurons [Haberstock-Debic et al. (2005), their Fig. 1 (http://www.jneurosci. org/cgi/content/full/25/34/7847/FIG1)]. In what can be considered the key experiment of the paper, Haberstock-Debic et al. then established the role of endocytosis in MOR redistribution. To achieve this, striatal neurons were transfected with an extracellular FLAG epitope-tagged MOR that was detected with a calcium-dependent anti-FLAG M1 antibody. Labeling of tagged receptors before drug treatment allowed the authors to follow the redistribution of surface-expressed receptors after stimulation. Like endogenous receptors, tagged MORs were redistributed in response to morphine or DAMGO [Haberstock-Debic et al. (2005), their Fig. $2 \mathrm{~A}$ (http://www.jneurosci.org/cgi/content/ full/25/34/7847/FIG2)]. Furthermore, application of DAMGO or morphine pre- 
vented striping of M1 antibodies from tagged MORs after their redistribution from the cell surface to transferrin-containing intracellular endosomes [Haberstock-Debic et al. (2005), their Fig. 2B$D]$. The authors then confirmed this observation using differential labeling of internalized and cell surface-expressed receptors under different transfection conditions [Haberstock-Debic et al. (2005), their Fig. 4 (http://www.jneurosci.org/ cgi/content/full/25/34/7847/FIG4)]. Finally, internalization of receptors was efficiently blocked by pretreating neurons with a MOR antagonist but not by preventing neuronal depolarization using tetrodotoxin, indicating that MOR endocytosis occurs in direct response to morphine [Haberstock-Debic et al. (2005), their Fig. 3 (http://www.jneurosci.org/cgi/content/ full/25/34/7847/FIG3)].

Because their previous in vivo observations (Haberstock-Debic et al., 2003) suggested that morphine-induced internalization may be restricted to dendrites, Haberstock-Debic et al. mapped the cellular distribution of internalized receptors in cultured striatal neurons using coimmunolocalization of MORs with the somatodendritic marker microtubuleassociated protein 2 as well as differential labeling of internalized and surfaceexpressed receptors. Interestingly, MOR internalization in response to DAMGO and morphine occurs in all neuronal compartments with the notable exception of proximal axons [Haberstock-Debic et al. (2005), their Figs. 5 (http://www. jneurosci.org/cgi/content/full/25/34/7847/ FIG5) and 6 (http://www.jneurosci.org/ cgi/content/full/25/34/7847/FIG6)].

Internalization of MORs in response to DAMGO in HEK293 cells is dependent on $\beta$-arrestins, whereas overexpression of GRK2 has been shown to allow morphine-induced MOR internalization in these same cells. To address the function of arrestins on MOR internalization in striatal neurons, Haberstock-Debic et al. transfected a hemagglutinin (HA)tagged dominant-negative $\beta$-arrestin-2 C-terminal fragment (HA $\beta$ Arr319-418) known to interfere with receptor internalization. As shown in the last figure of their paper [Haberstock-Debic et al. (2005), their Fig. 7 (http://www.jneurosci.org/ cgi/content/full/25/34/7847/FIG7)], expression of HAßArr319-418 prevents MOR internalization in response to both morphine and DAMGO, thus confirming the role of arrestins in this process. Finally, in an attempt to explain discrepancies between striatal neurons and HEK293

A
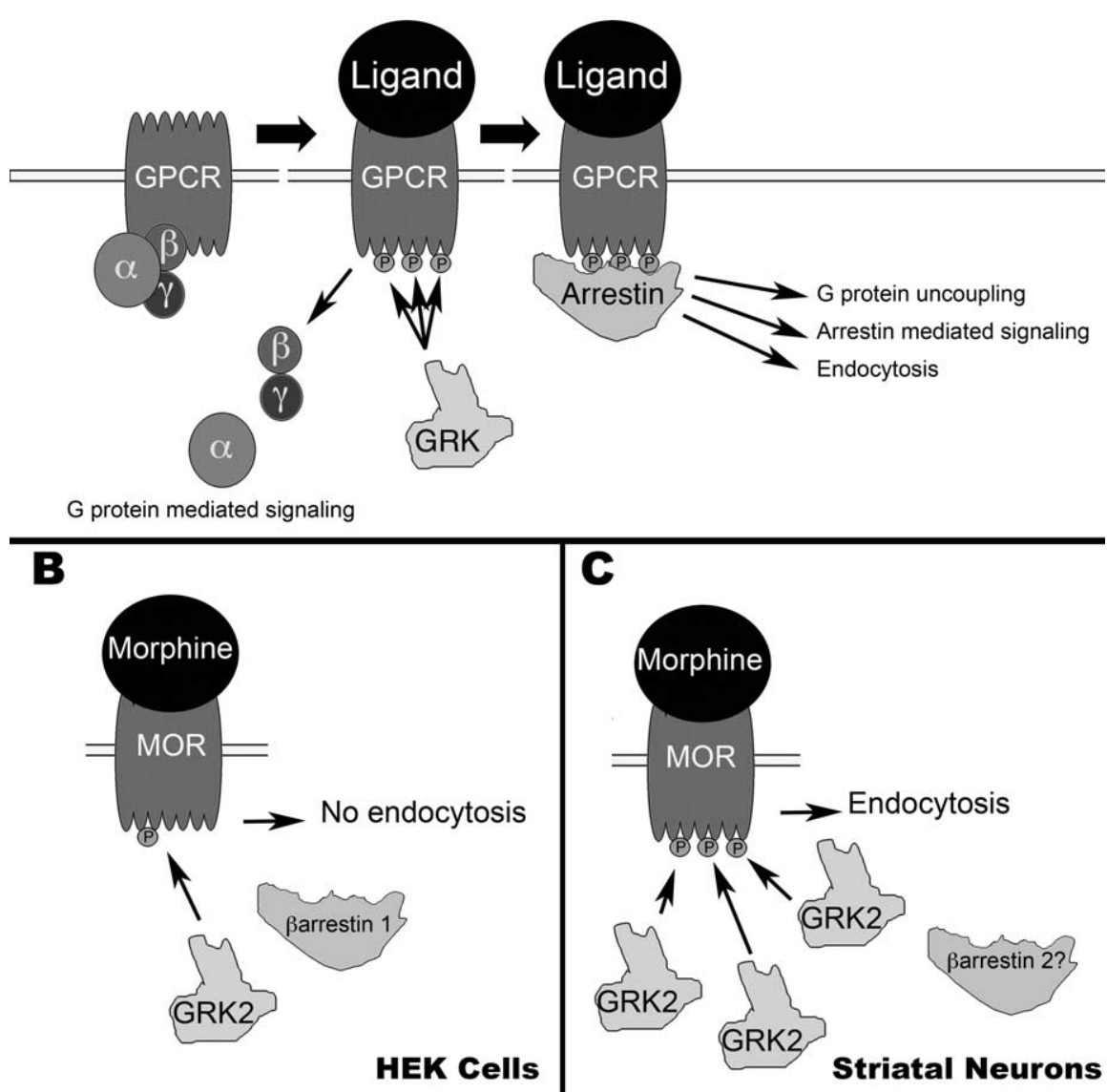

Figure 1. Model of GPCR regulation by arrestins and GRKs. $A$, After receptor activation by a ligand, GPCRs activate G-proteinmediated signaling and are phosphorylated at multiple sites by GRKs, resulting in the recruitment of arrestins. Interaction of GPCRs with arrestins results in uncoupling of G-protein-mediated signaling from GPCRs, receptor endocytosis, and formation of arrestin-dependent signaling complexes. $\boldsymbol{B}, \boldsymbol{C}$, Variations of gene expression between HEK cells, expressing low GRK2 levels along with $\beta$-arrestin-1 (B), and striatal neurons, expressing high GRK2 levels along with $\beta$-arrestin-2 ( $(\boldsymbol{)}$, may explain differences in MOR endocytosis in response to morphine in these cells.

cells, the authors compared the relative expression levels of $\beta$-arrestins and GRK2 in both cell types [Haberstock-Debic et al. (2005), their Fig. 7G,H]. Their results showed higher GRK2 expression in striatal neurons and the possible expression of distinct $\beta$-arrestin isoforms by these different cells (Fig. $1 B, C$ ).

The results presented by HaberstockDebic et al. strongly demonstrate the involvement of endocytosis in the redistribution of MORs in response to morphine in striatal neurons. A weak point of the study is that the exact molecular mechanism leading to differential morphineinduced MOR internalization in HEK293 cells and striatal neurons is left essentially uncharacterized. Measurements of expression levels for other GRKs or the use of an RNA interference-based strategy to explore the role of GRK2 in neuronal MOR internalization would have nicely complemented this work. Differences between the observations of HaberstockDebic et al. and previous observations made in other neuronal populations (Whistler et al., 1999), as well as the low levels of endocytosis in proximal axons of striatal neurons, also suggest that various neuronal types or distinct compartments of the same neuron may differ in the regulation of GPCR signaling. Overall, this article addresses a major issue in the field of opiate addiction and may explain the discrepancies observed between previous heterologous cell culture and animal studies. Biological systems are complex. The work of Haberstock-Debic et al. underscores the need to explore cellular signaling mechanisms in relevant cell types as well as in vivo to avoid potentially erroneous conclusions from studies conducted in heterologous cell systems. 


\section{References}

Beaulieu JM, Sotnikova TD, Marion S, Lefkowitz RJ, Gainetdinov RR, Caron MG (2005) An Akt/beta-arrestin 2/PP2A signaling complex mediates dopaminergic neurotransmission and behavior. Cell 122:261-273.

Bohn LM, Lefkowitz RJ, Gainetdinov RR, Peppel K, Caron MG, Lin FT (1999) Enhanced morphine analgesia in mice lacking betaarrestin 2. Science 286:2495-2498.

Bohn LM, Gainetdinov RR, Lin FT, Lefkowitz RJ,
Caron MG (2000) Mu-opioid receptor desensitization by beta-arrestin-2 determines morphine tolerance but not dependence. Nature 408:720-723.

Gainetdinov RR, Premont RT, Bohn LM, Lefkowitz RJ, Caron MG (2004) Desensitization of $G$ protein-coupled receptors and neuronal functions. Annu Rev Neurosci 27:107-144.

Haberstock-Debic H, Wein M, Barrot M, Colago EE, Rahman Z, Neve RL, Pickel VM, Nestler EJ, von Zastrow M, Svingos AL (2003) Morphine acutely regulates opioid receptor traf- ficking selectively in dendrites of nucleus accumbens neurons. J Neurosci 23:4324-4332.

Haberstock-Debic H, Kim K-A, Yu YJ, von Zastrow M (2005) Morphine promotes rapid, arrestin-dependent endocytosis of $\mu$-opioid receptors in striatal neurons. J Neurosci 25:7847-7857.

Whistler JL, Chuang HH, Chu P, Jan LY, von Zastrow M (1999) Functional dissociation of mu opioid receptor signaling and endocytosis: implications for the biology of opiate tolerance and addiction. Neuron 23:737-746. 